\title{
Produção animal em pastagem nativa submetida ao controle de plantas indesejáveis e a intensidades de pastejo
}

\author{
Animal production on native pasture submitted to the control of undesirable plants and grazing intensity
}

\author{
José Acélio Silveira da Fontoura Júnior ${ }^{\text {** }}$ Paulo César de Faccio Carvalho ${ }^{\mathrm{II}}$ Carlos Nabinger ${ }^{\mathrm{II}}$ \\ Jamir Luis Silva da Silva ${ }^{\mathrm{II}}$ Cassiano Eduardo Pinto ${ }^{\mathrm{III}}$ Leonardo Araripe Crancio ${ }^{\mathrm{III}}$
}

RESUMO

O objetivo deste trabalho, realizado no município de Cachoeira do Sul, região Fisiográfica da Serra do Sudeste do Rio Grande do Sul, foi estudar diferentes métodos de controle de espécies indesejáveis em pastagem nativa, associados a dois níveis de oferta de forragem, medindo suas eficiências em termos de resposta animal. Os tratamentos foram: testemunha $(T)$, roçada de primavera $(P)$, roçada de primavera + outono $(P+O)$ e roçada de primavera + controle químico $(P+Q)$, todos submetidos a dois níveis de oferta de forragem (8 e $14 \mathrm{~kg}$ de matéria seca $100 \mathrm{~kg}^{-1}$ de peso vivo por dia). O delineamento experimental utilizado foi o de fatorial em blocos completos casualizados $(4 \times 2)$, com duas repetições. Não houve efeito significativo de blocos nem interação dos fatores métodos de controle e níveis de oferta de forragem. O maior nível de oferta proporcionou maior ganho de peso vivo por área $(P<0,05)$. Os tratamentos $P$ e $P+Q$ proporcionaram maior ganho médio diário em relação ao $T(P<0,05)$. Os métodos de controle de plantas indesejáveis, assim como os níveis de oferta de forragem, não influenciaram a taxa de acúmulo diário de forragem e a taxa de desaparecimento $(P>0,05)$. Os resultados mostram que é possível manter o peso vivo de bovinos em pastagens nativas da Serra do Sudeste/RS, durante o período de inverno, utilizando práticas de manejo que assegurem nível mínimo de oferta de forragem e, ainda, que o manejo da pastagem nativa com roçada de primavera, com ou sem o uso de herbicida, proporciona melhor desempenho individual e menores perdas de peso no período hibernal.

Palavras-chave: desempenho animal, herbicida, oferta de forragem, roçada de outono, roçada de primavera.

\begin{abstract}
The aim of this experiment was to study different methods of controlling undesirable plants in native pastures, associated with two levels of herbage allowance, and their effects on animal production. The treatments were no control $(T)$, spring slashing $(P)$, spring+autumn slashing $(P+O)$ and spring slashing +chemical control $(P+Q)$, under two levels of herbage allowance (8 and $14 \mathrm{~kg}$ of dry matter $100 \mathrm{~kg}^{-1}$ of liveweight per day). The experimental design was a randomized complete block with two replicates. Not have block effects neither interaction between methods of control and herbage allowances $(P>0.05)$. The higher herbage allowance resulted in more liveweight gain per area $(P<0.05)$. The treatments $P$ and $P+Q$ showed greater individual liveweight gain in relation to $T$. The controlling methods the undesirable plants and the levels of herbage allowance did not affect dry matter accumulation rate neither the dry matter disappearance rate $(P>0.05)$. The results showed that it's possible to keep the live body weight of bovine in native pasture in Serra do Sudeste of Rio Grande do Sul/ Brazil, during the winter's period, utilizing management practices that secured a minimals levels of herbage allowance. These results showed also that the management of native pasture with slashing in spring, with or without chemical's controlling, it's provide a better individual development and less weight's lose in winter's period.
\end{abstract}

Key words: animal performance, slashing of the autumn, herbage allowance, herbicide, slashing of the spring.

\footnotetext{
I*Programa de Pós-graduação em Zootecnia, Universidade Federal de Pelotas (UFPel), Rua Félix da Cunha, 255/304, 96010-000, Pelotas, RS, Brasil. E-mail: jrmateador@yahoo.com.br.

IIDepartamento de Plantas Forrageiras, Faculdade de Agronomia, UFRGS, Porto Alegre, RS, Brasil. E-mail: paulocfc@vortex.ufrgs.br.

IIIAutônomo.
} 


\section{INTRODUÇÃO}

No Rio Grande do Sul, a pecuária de corte utiliza um sistema de exploração extensivo baseado quase que exclusivamente na pastagem nativa. Este recurso proporciona desempenho animal satisfatório na estação de crescimento (primavera-verão), mas, no outono e principalmente no inverno, as produções são baixas, em decorrência das alterações quantitativas e qualitativas da forragem, ocasionando baixos índices produtivos da pecuária de corte. A partir do fim do verão/início de outono (março) até o início da primavera (setembro), ocorre um declínio da qualidade da forragem do campo nativo, o qual se reflete na perda de peso dos animais, e que pode chegar a até $20 \%$ de peso vivo. Em regiões com invernos mais rigorosos e extensos, como nos Campos de Cima da Serra, as perdas de peso começam a ocorrer a partir da segunda quinzena de março e chegam a mais de $0,8 \mathrm{~kg} \mathrm{animal}^{-1}$ dia ${ }^{-1}$ no mês de julho (GROSSMAN \& MOHRDIECK, 1956).

O conceito errôneo de que lotação seja sinônimo de produtividade é um dos causadores da baixa produtividade da pastagem nativa. Todo o recurso forrageiro, colhido através do pastejo, tem uma capacidade de suporte limitada pela sua velocidade de crescimento, a qual depende dos componentes bióticos e abióticos formadores do ecossistema pastoril. O conhecimento da fisiologia das principais espécies componentes da pastagem é fundamental para o sucesso do seu manejo.

Segundo NABINGER (2002), a interceptação da radiação solar pela vegetação é a primeira condição para a constituição do fluxo de energia do sistema, sendo esta dependente da área foliar, ou seja, das folhas verdes que são a parte fotossintetizadora das plantas. Ao mesmo tempo, essas folhas precisam ser consumidas pelos herbívoros em sua alimentação, o que representa o grande dilema em manejo de pastagem. No entanto, existe um grau de utilização das pastagens, no qual é possível conciliar um ótimo crescimento dessas folhas da pastagem com uma satisfatória produção animal, otimizando, desta forma, o fluxo de energia no sistema, com benefícios para todos os seus componentes. Esse grau de utilização pode ser obtido, por exemplo, manipulando-se a carga animal em função da oferta de forragem (intensidade de pastejo).

Um outro fator que pode influenciar a produtividade das pastagens nativas é a presença de espécies indesejáveis que, embora podendo ser pertencentes a esse ecossistema, não fazem parte de forma contínua da dieta animal. Por isso, dentro do contexto produção animal, essas plantas são denominadas de indesejáveis. Essas espécies, além de não contribuírem para a alimentação animal, competem por recursos e ainda ocupam área, diminuindo, deste modo, o rendimento das espécies desejáveis, acarretando redução da capacidade de suporte da pastagem.

Nas pastagens nativas do Rio Grande do Sul, as principais espécies indesejáveis nativas são a carqueja (Baccharis trimera), a chirca (Eupatorium buniifolium), o alecrim-do-campo (Vernonia nudiflora), o mio-mio (Baccharis coridifolia), o caraguatá (Eryngium horridum) e o caraguatá-dobanhado (Eryngium pandalifolium). Dentre os métodos de controle de espécies indesejáveis existentes, podem-se destacar o pastejo, a roçada, o arraste de trilhos, o arranquio, os herbicidas e a fertilização, além do fogo. GOMES et al. (2000) observaram que a adubação melhora a condição da pastagem porque diminui a freqüência de espécies não desejáveis e aumenta a das espécies forrageiras, como as leguminosas nativas.

RASSINI \& COELHO (1994) observaram que a mistura de $2,4 \mathrm{D}+$ picloran a $4 \%$ no toco, a $10 \%$ em anelamento e a $2 \%$ em pulverização foliar, na espécie assa-peixe (Vernonia polyanthes), controlou a planta daninha em todas as modalidades e doses de aplicação. CASTILHOS (1993) observou redução no percentual de contribuição de Aristida ssp. e de Baccharis trimera, na matéria seca total de uma pastagem natural submetida aos tratamentos de roçada, pastejo e queima, com e sem adubação.

A maioria das informações referentes ao controle de espécies indesejáveis disponíveis na literatura não insere a produção animal como variável resposta. Sendo assim, o presente trabalho objetivou avaliar a eficiência de diferentes métodos de controle a partir da resposta animal em pastagem nativa manejada sob duas ofertas de forragem, uma vez que a pressão de pastejo pode interagir com os tratamentos físicos e/ ou químicos de controle.

\section{MATERIAL E MÉTODOS}

Este experimento foi conduzido em uma propriedade particular, distrito de Santana da Boa Vista, pertencente ao município de Cachoeira do Sul, região Fisiográfica da Serra do Sudeste do Rio grande do Sul, de 31 de maio a 16 de setembro de 2002, totalizando 109 dias de avaliação, com utilização da pastagem dividida em três sub-períodos de 42, 25 e 42 dias. O solo é de origem granítica, com baixa proporção de argila (13 a $14 \%)$, baixa disponibilidade de fósforo $\left(3,7 \mathrm{mg} \mathrm{L}^{-1}\right)$,

Ciência Rural, v.37, n.1, jan-fev, 2007. 
potássio suficiente $\left(125 \mathrm{mg} \mathrm{L}^{-1}\right)$, baixa a média matéria orgânica (2,8\%) ebaixa CTC $\left(8,5 \mathrm{cmol} \mathrm{L}^{-1}\right)$. O experimento foi desenvolvido em uma pastagem natural, com dominância do estrato superior, composto principalmente por carqueja, alecrim-do-campo e presença menos importante de Psidium luridum (araçádo-campo) e Andropogon lateralis (capim-caninha). Predominam no estrato inferior: Paspalum notatum (grama-forquilha), Axonopus affinis (grama-tapete), entre as gramíneas, e Desmodium incanum (pegapega), Arachis burkartii e Stylosanthes leiocarpa, entre as leguminosas. As unidades experimentais (UE) foram constituídas por 16 piquetes com área média de 2,63ha, em uma área experimental total de 42,1ha. A área disponível para os animais reguladores era adjacente à área experimental. O delineamento experimental utilizado foi um fatorial em blocos ao acaso (4 x 2), com duas repetições.

Os tratamentos constaram de métodos de controle assim designados: tratamento testemunha ( $\mathrm{T}$ ), roçada de primavera $(\mathrm{P})$, roçada de primavera + outono $(\mathrm{P}+\mathrm{O})$, roçada de primavera mais controle químico $(\mathrm{P}+\mathrm{Q})$, associados a dois níveis de oferta de forragem (média $=8 \%$ ou $8 \mathrm{~kg}$ de matéria seca $100 \mathrm{~kg}$ de peso vivo $\mathrm{dia}^{-1}$, e alta $=14 \%$ ou $14 \mathrm{~kg}$ de matéria seca $100 \mathrm{~kg}$ de peso vivo por dia-1), totalizando oito tratamentos. As roçadas de primavera foram feitas na segunda quinzena de outubro de 2001 e a roçada de outono e o controle químico na segunda quinzena de abril de 2002.

O método de pastejo utilizado foi o contínuo com lotação variável, com ajuste periódico da carga animal, com o objetivo de manter uma oferta de forragem constante, através da técnica de "put and take” (MOTT \& LUCAS, 1952). Em cada piquete foi mantido um número mínimo de três animais-teste e um número variável de animais reguladores, de acordo com a oferta de forragem pretendida. Foram utilizadas novilhas com idade média de 18 meses e peso médio inicial de $230,7 \mathrm{~kg}$, predominando o cruzamento entre Charolês e raças zebuínas. A estimativa de massa de forragem foi realizada através da metodologia de dupla amostragem com padrões de 1 a 5 (HAYDOCK \& SHAW, 1975). Estabeleceram-se diferentes padrões para o tratamento testemunha e para os demais tratamentos. Realizaram-se entre 60 e 90 avaliações visuais por UE, desconsiderando a massa das espécies indesejáveis. A taxa de acúmulo diária (TAD) da pastagem foi estimada através da técnica proposta por MORAES et al. (1990), utilizando-se três gaiolas de exclusão por piquete, realocadas a cada 28 dias. A diferença de matéria seca entre as amostragens efetuadas dentro da gaiola e as amostragens fora da gaiola realizadas no início do período imediatamente anterior, dividida pelo número de dias do referido período, forneceu a taxa de acúmulo da pastagem, em kg de MS ha ${ }^{-1}$ dia $^{-1}$. As taxas de desaparecimento de matéria seca (TD) foram calculadas subtraindo-se quantidade de MS dentro da gaiola pela quantidade de MS fora da gaiola na data de amostragem, dividindose o resultado pelo número de dias do período.

Os animais foram pesados no início do experimento e, periodicamente, para ajuste da carga (42, 25 e 42 dias), conforme oferta de forragem pretendida e determinação do ganho médio diário (GMD). Nas pesagens inicial e final, os animais foram submetidos a jejum prévio de 16 horas. A determinação do GMD foi obtida a partir dos animais-teste. A carga animal foi obtida pelo somatório dos pesos de todos os animais presentes em cada potreiro (testes + reguladores), dividindo este pela área de cada um dos potreiros, sendo os valores expressos em $\mathrm{kg}$ de PV/ha. Dividindo-se o valor da carga média pelo peso médio dos animais testes e multiplicando-se o resultado pelo número de dias do período considerado, obteve-se a variável animais.dia ha-1 ${ }^{-1} \mathrm{O}$ produto da variável animais.dia ha-1 pelo ganho médio diário (GMD) dos testes no período constitui o ganho de peso vivo por hectare. O controle sanitário consistiu em vacinação contra aftosa e carbúnculo, vermífugo (a cada 45 dias) e controle permanente de ectoparasitas. $\mathrm{O}$ fornecimento de água e sais minerais foi à vontade durante todo o período experimental. Os dados foram submetidos à análise de variância, através da comparação de médias pelo teste de Tukey a um nível de significância de 5\%, utilizando-se o aplicativo SAS (SAS, 1994) para o delineamento preconizado.

\section{RESULTADOS E DISCUSSÃO}

A interação entre os fatores métodos de controle e níveis de oferta de forragem não foi significativa $(\mathrm{P}=0,06)$; portanto, a discussão será feita para cada fator separadamente. Na tabela 1, são apresentados os valores médios relacionados às produções animal e vegetal, para os níveis de oferta de forragem. A variável oferta de forragem apresentou diferença significativa $(\mathrm{P}<0,0001)$ entre os tratamentos $8 \%$ e $14 \%$, sendo as ofertas efetivamente obtidas da ordem de $10,2 \%$ e $15,2 \%$, respectivamente, o que vem ao encontro da proposta inicial do trabalho, pois era condição fundamental a diferença entre os níveis desse fator. Outras variáveis que também apresentaram diferenças significativas, tais como carga animal, animais.dia ha-1 e massa de forragem (MF), são conseqüências dos níveis de oferta aplicados como tratamento; portanto, a diferença era esperada. 
Tabela 1 - Ganho médio diário (GMD, $\mathrm{kg} \mathrm{an}^{-1} \mathrm{dia}^{-1}$ ), carga animal (Carga, $\mathrm{kg}_{\text {de }} \mathrm{PV} \mathrm{ha}{ }^{-1}$ ), ganho de peso vivo por área (GPV, kg de PV ha ${ }^{-1}$ ), número de animais por hectare por dia (an.dia ha ${ }^{-1}$ ), massa de forragem (MF, kg de MS ha ${ }^{-1}$ ), taxa de acúmulo diário (TAD, kg de $\mathrm{MS} \mathrm{ha}^{-1}$ ), taxa de desaparecimento (TD, kg de MS ha ${ }^{-1}$ ) e oferta real (OF, kg de MS $100 \mathrm{~kg}^{-1}$ de PV por dia), segundo níveis de oferta de forragem (média de 8 unidades experimentais).

\begin{tabular}{|c|c|c|}
\hline Variáveis & $\begin{array}{c}8 \% \\
\text { (8 kg de MS } 100 \mathrm{~kg}^{-1} \text { de PV por dia) }\end{array}$ & $\begin{array}{c}14 \% \\
\left(14 \mathrm{~kg} \text { de MS } 100 \mathrm{~kg}^{-1} \text { de PV por dia) }\right.\end{array}$ \\
\hline GMD, $\mathrm{kg} \mathrm{an}^{-1} \mathrm{dia}^{-1}$ & $-0,059$ & $-0,003$ \\
\hline Carga, kg de PV ha ${ }^{-1}$ & 354 a & $290 \mathrm{~b}$ \\
\hline GPV, kg ha-1 & $-13,6 b$ & 1,9 a \\
\hline An.dia ha ${ }^{-1}$ & $175,0 \mathrm{a}$ & $134,2 \mathrm{~b}$ \\
\hline MF, Kg de MS ha ${ }^{-1}$ & 2245 b & 2789 a \\
\hline TAD, Kg de MS ha ${ }^{-1}$ & 4,0 & 5,7 \\
\hline TD, Kg de MS ha-1 & 7,5 & 12,7 \\
\hline Of, kg de MS $100 \mathrm{~kg}^{-1}$ de PV por dia & $10,2 \mathrm{~b}$ & $15,2 \mathrm{a}$ \\
\hline
\end{tabular}

${ }^{1}$ Médias, na linha, seguidas por diferentes letras diferem estatisticamente $(\mathrm{P}<0,05)$ pelo teste de Tukey.

SOARES (2002), trabalhando com níveis de oferta de forragem, observou diferença significativa para a variável MF, na primavera. O autor salientou que a massa aumenta à medida que a oferta é aumentada. Já para o período de inverno, o mesmo autor constatou diferenças apenas do nível alto (16\%) em relação aos demais níveis fixos utilizados (8\% e 12\%), sendo que estes não diferiram entre si. Para a variável carga animal, o mesmo autor não encontrou diferença significativa pela análise de variância, sendo os valores obtidos de 365, 297 e 484kg de PV ha-1 ${ }^{-1}$ respectivamente, para as ofertas de 8, 12 e 16\%. SETELICH (1994), para a mesma variável, encontrou efeito linear negativo em função dos níveis de oferta (4, 8, 12 e 16\%). A variável animais.dia/ha, que apresentou diferença significativa $(\mathrm{P}=0,006)$, está diretamente relacionada à carga animal. Esta variável permite comparação com outros trabalhos, já que leva em consideração a duração do período experimental.

Houve diferença entre ofertas quanto à variável GPV ha ${ }^{-1}(\mathrm{P}<0,05)$, sendo que, para o tratamento de maior oferta, houve um pequeno ganho, enquanto o de baixa oferta registrou perda. Embora o tratamento de alta oferta apresente uma menor carga, essa superioridade em GPV é explicada pelo maior GMD desse nível, principalmente no último período de avaliação, que foi bastante expressivo (chegando a mais de $200 \mathrm{~g} \mathrm{dia}^{-1}$ animal $^{-1}$ ), elevando assim o GMD médio do período. Esse resultado nos permite afirmar que é possível manter o peso vivo de bovinos, na região estudada, no período de inverno, com ajustes de carga animal em função da massa de forragem disponível. SOARES (2002) observou valores negativos no GPV,

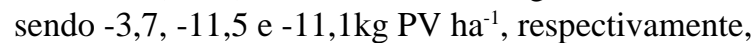
para 8,12 e $16 \%$ de oferta de forragem, no período de inverno. No mesmo trabalho, o autor ressalta que o único tratamento que registrou ganho foi o que teve variação na oferta de forragem de $8 \%$ para $12 \%$ do PV ( $8 \%$ na primavera e $12 \%$ no restante do ano), conseqüência do maior GMD neste tratamento. Isso evidencia a importância da estrutura da pastagem, mostrando que não é somente o nível de oferta que define produtividade animal em pastagem. RIZO et al. (2004), no município de Bagé, RS, registrou ganhos que variaram de 5 a $9 \mathrm{~kg}$ de PV/ha, durante o período de inverno (27/05 a 22/09/1999), para uma oferta pretendida de 10\%. MOOJEN (1991) não encontrou diferença significativa para GPV no inverno, entre níveis de oferta. O autor registrou perdas que variaram de 15 a $39 \mathrm{~kg}$ de $\mathrm{PV} \mathrm{ha}{ }^{-1}$. As perdas registradas, ou mesmo pequenos ganhos, são devidos à baixa qualidade da oferta de forragem disponível, visto que, em pastagens nativas, predominam espécies estivais, que, com a queda de temperatura e a ocorrência de geadas, param o crescimento e diminuem seu valor nutricional.

A variável GMD não apresentou efeito significativo $(\mathrm{P}>0,05)$ para níveis de oferta de forragem, sendo que, em alta oferta, o ganho foi praticamente nulo e, na mais baixa oferta, houve pequena perda de peso. Esse resultado mostra que, em nível de campo, ao se garantir um nível mínimo de oferta de forragem, é possível manter peso vivo em bovinos. Os dados deste experimento são bastante semelhantes aos de SOARES (2002) para níveis fixos de oferta de forragem de 8, 12 e $16 \%$, que registrou pequenas perdas, $-0,043,-0,083 \mathrm{e}-$ $0,069 \mathrm{~kg} \mathrm{an}^{-1} \cdot \mathrm{dia}^{-1}$, sem efeito significativo entre tratamentos.

Os valores de taxa de acúmulo diário (TAD) não apresentaram diferenças significativas $(\mathrm{P}>0,05)$ para níveis de oferta de forragem. A TAD apresentou

Ciência Rural, v.37, n.1, jan-fev, 2007. 
valores irrisórios, o que já era esperado por tratar-se de período hibernal, quando as baixas temperaturas e menor luminosidade praticamente não permitem crescimento em pastagens naturais, onde predominam espécies de crescimento estival. Os valores encontrados no presente trabalho são concordantes com os de RIZO et al. (2004), que obtiveram crescimento médio de 2,20kg de MS ha-1, em Bagé, RS, durante o período de inverno. SOARES (2002) observou valores também muito semelhantes, porém, encontrou efeito significativo, sendo o tratamento $16 \%$ superior aos de 12 e $8 \%$ de oferta de forragem, e estes não diferiram entre si. Os valores obtidos pelo autor são, respectivamente, 4,9; 0,4 e 0,8kg de MS ha-1. Os dados referentes à taxa de desaparecimento (TD) não apresentaram efeito significativo $(\mathrm{P}>0,05)$ para níveis de oferta de forragem.

Na tabela 2, são apresentadas as variáveis de produção animal e vegetal, conforme tratamentos de controle de espécies indesejáveis. O GMD nos tratamentos de controle $\mathrm{P}$ e $\mathrm{P}+\mathrm{Q}$ foram superiores $(\mathrm{P}<0,013)$ ao tratamento $\mathrm{T}$, ficando o tratamento $\mathrm{P}+\mathrm{O}$ em posição intermediária. Os resultados sugerem que a roçada de primavera, independentemente da associação com outros métodos, é uma ferramenta prática para melhorar o desempenho individual de bovinos em pastagem nativa da região. A perda de peso no tratamento $\mathrm{P}+\mathrm{O}$ explica-se, possivelmente, pelo fato de a roçada de outono ter sido feita pouco antes do início do período experimental. Isso ocasionou, além de um acúmulo de material morto sobre a pastagem, uma remoção na qualidade da massa de forragem, visto que removeu principalmente as lâminas foliares, parte superior do dossel. A considerável perda de peso no tratamento $\mathrm{T}\left(-0,150 \mathrm{~kg} \mathrm{an}^{-1} \mathrm{dia}^{-1}\right)$ pode achar sustentação em maior dispêndio de tempo e energia na busca do alimento, em comparação com os outros tratamentos, pois possivelmente o consumo tenha diminuído devido ao aumento no tempo de procura, o que é somente compensado de forma parcial, com o aumento do tempo de pastejo (CATON \& DHUYVETTER, 1997). Essa argumentação, associada ao melhor desempenho nos tratamentos $\mathrm{P}$ e $\mathrm{P}+\mathrm{Q}$, reforça a importância do controle de espécies indesejáveis quando objetiva-se melhor desempenho animal.

Houve diferença significativa da variável carga animal $(\mathrm{P}<0,011)$ do tratamento $\mathrm{T}$ para os demais. A variável animais.dia ${ }^{-1} h a$, embora não tenha apresentado efeito significativo ( $\mathrm{P}>0,05)$, numericamente acompanha a carga animal, pois a amplitude de variação tem no tratamento T o seu ápice, sendo que os demais são bastante semelhantes.

O GPV apresentou efeito significativo $(\mathrm{P}<0,013)$ e foi superior no tratamento $\mathrm{P}$, quando comparado com $\mathrm{T}$ e $\mathrm{P}+\mathrm{O}$, não sendo diferente de $\mathrm{P}+\mathrm{Q}$. $\mathrm{O}$ tratamento $\mathrm{P}+\mathrm{Q}$ também não diferiu do tratamento $\mathrm{P}+\mathrm{O}$. O tratamento $\mathrm{T}$ foi inferior aos demais, não diferindo apenas do $\mathrm{P}+\mathrm{O}$. A superioridade do tratamento $\mathrm{P}$ encontra suporte no GMD que, embora não difira estatisticamente do $\mathrm{P}+\mathrm{Q}$, é 56\% superior em valor, o que, para a produção animal, é considerável. Como não há diferença entre as cargas e o GPV é o produto entre GMD e carga, fica evidente que a superioridade deste tratamento em GPV está suportada no maior GMD. Mesmo tendo carga animal mais elevada, o tratamento $T$ foi inferior aos demais em GPV, não diferindo apenas de $\mathrm{P}+\mathrm{O}$ por apresentar um GMD muito baixo (-0,152).

A massa de forragem (MF) apresentou diferença significativa $(\mathrm{P}<0,012)$, sendo superior no

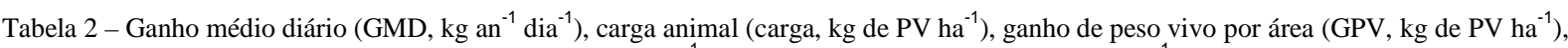
número de animais por hectare por dia (an.dia ha ${ }^{-1}$ ), massa de forragem (MF, $\mathrm{kg}_{\text {de }} \mathrm{MS} \mathrm{ha}^{-1}$ ), taxa de acúmulo diário (TAD, $\mathrm{kg}$ de MS ha ${ }^{-1}$ ), taxa de desaparecimento (TD, kg de MS ha ${ }^{-1}$ ) e oferta real (OF, kg de MS $100 \mathrm{~kg}^{-1}$ de PV por dia), segundo tratamentos de controle (média de 4 unidades experimentais).

\begin{tabular}{|c|c|c|c|c|}
\hline \multirow[b]{2}{*}{ Variáveis } & $\mathrm{T}$ & $\mathrm{P}$ & $\mathrm{P}+\mathrm{O}$ & $P+Q$ \\
\hline & Testemunha & Roçada de primavera & Roçada de outono & $\begin{array}{c}\text { Roçada de primavera }+ \text { controle } \\
\text { químico }\end{array}$ \\
\hline GMD, $\mathrm{kg} \mathrm{an}^{-1} \mathrm{dia}^{-1}$ & $-0,152 b$ & $0,072 \mathrm{a}$ & $-0,092 a b$ & 0,046 a \\
\hline Carga, kg de PV ha ${ }^{-1}$ & 369 a & $297 \mathrm{~b}$ & $309 \mathrm{~b}$ & $313 \mathrm{~b}$ \\
\hline GPV, kg de PV ha ${ }^{-1}$ & $-29,3$ c & 8,3 a & $-14,0$ bc & $4,1 \mathrm{ab}$ \\
\hline An.dia ha ${ }^{-1}$ & 178,0 & 144,7 & 150,5 & 145,2 \\
\hline MF, kg de MS ha-1 & 3172 a & $2333 \mathrm{~b}$ & 2217 b & 2346 b \\
\hline TAD, kg de MS ha-1 & 6,17 & 3,57 & 6,40 & 3,27 \\
\hline TD, kg de MS ha ${ }^{-1}$ & 11,05 & 8,22 & 9,52 & 11,70 \\
\hline Of, kg de MS $100 \mathrm{~kg}^{-1}$ de PV por dia & 13,72 & 12,70 & 12,52 & 11,77 \\
\hline
\end{tabular}

${ }^{1}$ Médias, na linha, seguidas por diferentes letras diferem estatisticamente $(\mathrm{P}<0,05)$ pelo teste de Tukey.

Ciência Rural, v.37, n.1, jan-fev, 2007. 
tratamento T. Os demais tratamentos não apresentaram diferença entre si. A maior MF para o tratamento T, embora nas avaliações de massa fossem desprezadas as espécies indesejáveis, deve-se ao fato de a forragem estar inacessível ao pastejo pela presença destas espécies. A maior MF justifica a maior carga animal suportada por esse tratamento. Observa-se que a presença de espécies indesejáveis pode induzir o uso de maiores cargas; entretanto, o desempenho animal é prejudicado em tal circunstância. Em contrapartida, ao trabalhar-se com cargas mais baixas, nessa situação, pode-se aumentar a freqüência de espécies indesejáveis. Em situações de média a alta freqüência de espécies indesejáveis, é recomendado o seu controle. Nesse caso, para as condições pesquisadas, a roçada de primavera é uma alternativa recomendável. Salienta-se que a eliminação dessas espécies não é desejável, por fazerem parte do ecossistema campo nativo e por terem, conseqüentemente, funções específicas nele.

\section{CONCLUSÕES}

É possível manter o peso de bovinos em pastagens nativas da Serra do Sudeste, RS, durante o período de inverno, utilizando práticas de manejo que assegurem nível mínimo de oferta de forragem. Para tanto, é fundamental trabalhar-se com cargas ajustadas de acordo com a oferta de forragem disponível.

O manejo da pastagem nativa com roçada de primavera, com ou sem o uso de herbicida, proporciona melhor desempenho individual e menores perdas de peso no período hibernal.

\section{AGRADECIMENTOS} do projeto.

À Empresa Dow Agrosciences, pelo financiamento

\section{REFERÊNCIAS}

CASTILHOS, Z.M.S. Controle de espécies indesejáveis na pastagem natural. In: FEDERACITE - IV. Campo nativo, melhoramento e manejo. Porto Alegre: Caramuru, 1993. p.62-71.

CATON, J.S.; DHUYVETTER, D.V. Influence of energy supplementation on grazing ruminants: requirements and responses. Journal of Animal Science, Champaign, v.75, p.533-542, 1997

GOMES, K.E. et al. Dinâmica de uma pastagem natural em função de níveis de oferta de forragem, diferimentos e adubação. In: REUNIÃO DO GRUPO TÉCNICO EM FORRAGEIRAS DO CONE SUL - ZONA CAMPOS. Dinâmica da vegetação em ecossistemas pastoris, 2000, Guarapava, PR. Anais... Guarapuava: Grupo Técnico em Forrageiras do Cone Sul, 2000. p.160-162.

GROSSMAN, J.; MOHRDIECK, K.H. Experimentação forrageira do Rio Grande do Sul. Porto Alegre: Secretaria da Agricultura, Diretoria da Produção Animal, 1956. p.115122.

HAYDOCK, K.P.; SHAW, N.H. The comparative yield method for estimating dry matter yield of pasture. Australian Journal of Experimental Agriculture and Animal Husbandry, Melbourne, v.15, p.66-70, 1975.

MOOJEN, E.L. Dinâmica e potencial produtivo de uma pastagem nativa do Rio Grande do Sul submetida a pressões de pastejo, épocas de diferimento e níveis de adubação. 1991. 172f. Tese (Doutorado em Plantas Forrageiras) - Curso de Pós-graduação em Zootecnia, Universidade Federal do Rio Grande do Sul.

MORAES, A. et al. Comparação de métodos de taxa de crescimento em uma pastagem submetida a diferentes pressões de pastejo. In: REUNIÃO ANUAL DA SOCIEDADE BRASILEIRA DE ZOOTECNIA, 27., 1990, Campinas. Anais... Campinas: SBZ, 1990. p.332.

MOTT, G.O.; LUCAS H.L. The design, conduct, and interpretation of grazing trials on cultivated and improved pastures. In: INTERNATIONAL GRASSLAND CONGRESS, 6, 1952, Pensylvania. Proceedings... Pensylvania: State College, 1952. p.1380-1385.

NABINGER, C. 2002 Sistemas de pastoreio e alternativas de manejo de pastagens. In: CICLO DE PALESTRAS EM PRODUÇÃO E MANEJO DE BOVINOS. Ênfase: Manejo reprodutivo e sistemas de produção em bovinos de corte. 7, 2002, Canoas. Anais... Canoas: Ulbra, 2000. p.7-60.

RASSINI, J.B.; COELHO, R.R. Controle químico de assa-peixe (Vernonia polyanthes) em pastagens. Revista Brasileira de Zootecnia, Viçosa, v.6, p.1994-6871, 1994.

RIZO, L.M. et al. Desempenho de pastagem nativa e pastagem sobre-semeada com forrageiras hibernais com e sem glifosato. Ciência Rural, Santa Maria, v.34, n.6, p.1921-1926, 2004.

SAS INSTITUTE. User’s guide: version 6. Cary, 1994. 1028p.

SETELICH, E.A. Potencial produtivo de uma pastagem natural do Rio Grande do Sul, submetida a distintas ofertas de forragem. 1994. 169f. Dissertação (Mestrado em Plantas Forrageiras) - Curso de Pós-graduação em Zootecnia, Universidade Federal do Rio Grande do Sul.

SOARES, A.B. Efeito da alteração da oferta de matéria seca de uma pastagem natural sobre a produção animal e a dinâmica da vegetação. 2002. 180f. Tese (Doutorado em Plantas Forrageiras) - Curso de Pós-graduação em Zootecnia, Universidade Federal do Rio Grande do Sul. 